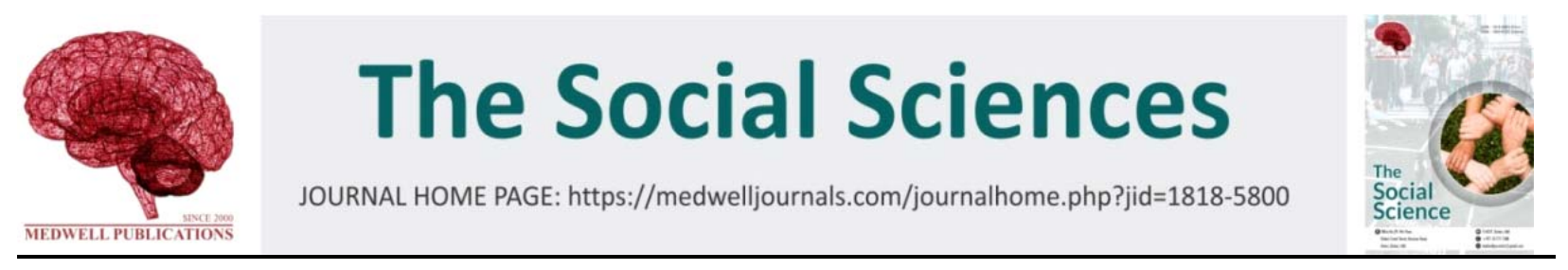

\title{
Proactive Aggression in Middle School Students
}

\author{
Karim Fakhry, Helal and Bouchra Hussein Aboud \\ Department of Educational and Psychological Sciences, University Babylon, \\ College of Education for Human Sciences, Hillah, Iraq
}

\begin{abstract}
Key words: Psychological conflicts, segments, anger, society, possession, directed
\end{abstract}

\section{Correspoding Author: \\ Karim Fakhry \\ Department of Educational and Psychological Sciences, University Babylon, College of Education for Human Sciences, Hillah, Iraq}

Page No: 38-44

Volume 15: Issue 1, 2020

The Social Science

ISSN (P): 1818:5800

Copy Right: @ Medwell Publication

\begin{abstract}
That life and societies in a steady change because of the movement and the pace of scientific progress rapid would change the nature of the individual's thinking and trends and values and beliefs and deal with others and this would be a bit of psychological conflicts, especially, among adolescents because they are the most vulnerable segments of society. They can be directed towards a goal without requiring the individual to show his anger and can be directed towards possession of objects or directed to control individuals. Pre-emptive aggression is linked to quarrels, attacks and harmful actions to achieve. The goal of trying to achieve or be oriented towards a peer to increase social status.
\end{abstract}

\section{INTRODUCTION}

Therefore, the current research seeks to identify the levels proactive aggression among middle school students in the center of Babil province. Therefore, the researcher has constructed a measure of proactive aggression and adopted the definition by Acet for proactive aggression. The researcher investigated the validity and stability of these two measures and statistically analyzed their scores on a sample of (400) second grade students who were chosen by the random stratified method. After completing the preparation of the research tools, the researcher applied them to a sample of (458) randomly selected. In order to analyze the results of the research, the researcher used a set of statistical means to achieve the objectives of the research is the t-test one sample and the testing of two independent samples, Pearson correlation coefficient, alfa Cronbach coefficient, Pearson correlation coefficient, simple linear regression analysis equation. The researcher reached the following results:

- The low level of proactive aggression among middle school students

- There is a positive correlation in the proactive aggression among students in the middle stage
Based on the results of the research, the researcher developed a set of recommendations and proposals that will complement the current research.

\section{Chapter I/definition of research}

Research problem: Aggression is one of the most widespread psychological and social problems of children and adolescents because it is a broad phenomenon in terms of variation, direction and expression. All people who are born in human society show this feeling towards other people and groups. This feeling may be directly or indirectly strong or weak, public or otherwise, according to his feelings of aggression [1, 30].

In many studies, aggressive behavior is one of the most behavioral problems in it, leading some students to commit hostile practices such as competition with peers as well as constraints imposed by the school system and the existence of elements of frustration. Teenagers are interested in middle school students aged between 13 and 15 years which are important in human life and represent an important part of adolescence. They are characterized by different changes (psychological, biological, social) Quiroz et al. (2006) There is no doubt that enemy behavior. This is a real reality that exists in most countries of the world. It is occupied by all the workers in the field 
of education in general and society in general. It takes time from school administrations and leaves negative effects on the educational process. Governmental institutions or institutions of civil society or private because it is a social phenomenon in the first place and its negative effects affect the entire society [3, 204].

Stryy and Slaby show that proactive aggression against school students, especially, adolescents has negative effects on mental health. In his view, premeditated aggression is a behavioral problem with dangerous effects on adolescents. The teenager may be the victim of aggression. Lack of self-esteem, social isolation, absence from school and drop in scholastic achievement [4, 191].

Pre-emptive aggression is a serious factor in the occurrence of later delinquency and behavior disorders. Pre-emptive aggression is directed towards a goal without requiring an individual to show his anger and can be directed towards possession of objects or directed to control individuals. Pre-emptive aggression is linked to quarrels, attacks and actions harmful to achieve a goal sought or directed towards peers to increase social status $[5,51]$.

And by the open questionnaire that was presented to a number of students and the researcher's visit to some middle schools and to meet the principals of these schools and their principals, educational counselors, teachers and teachers and inquire about the size of this phenomenon among the students, most of them referred to the spread of aggression in their schools and take different forms and pictures, education punishment by teachers for students.

The current research looks for the effects of the concept of proactive aggression which are reflected in the fields of education, social, psychological and health, the researcher believes that it is necessary to study this variable.

Research importance: Adolescence is characterized as an acute emotional stage characterized by strength and intensity due to changes in the physiological and glandular of the adolescent as well as social and cultural factors and here highlights the role of parents in the emotional effects of adolescence whenever the relationship of parents is equal and the more wellprepared environmental and social experiences increased his chance to pass this stage. More appropriately, either if they were marked.

The relationship with cruelty and abuse leads to the adolescent becoming more agitated and aggressive and has anti-social behavior. The teenager's emotions are characterized by force, insensitivity and inconsistency. He may sometimes feel happy and sometimes become too preoccupied [6, 37].

Various studies indicate that each type of aggressive behavior can be associated with a specific pattern of social cognition. Pre-emptive aggression which is expected to receive reward or reward is correlated with the expectations of the positive results of aggression $[38,5]$.

The utility or goal of pre-emptive aggression is linked to the narcissistic or grandeur schemes that imply a desire for the need to obtain or possess everything that can be important in pre-emptive aggressive behavior that is usually directed towards a particular objective [520,7].

Dodge et al. (1997) argues that anticipatory aggression is characterized by being more controlled and controlled by the individual, not very angry, organized at a high level and being astute or passive through the existence of a goal being pursued as a kind of reward or benefit [ 264.5].

Studies have shown that the punishment, whether physical or psychological, leads to aggression. These studies include Cross which showed that severe punishment led to aggressive behavior in children and a study by Samual. Teenage aggressors were severely punished by their parents [337. 8].

The importance of this study shows the need to identify the nature of pre-emptive aggression and the resulting effects, may be given useful information for teachers, principals, parents and those interested in the field of education which helps them to determine the most appropriate ways and means for the purpose of finding a professional mechanism for preventive and therapeutic intervention based on accumulated scientific expertise and knowledge minute of the problems experienced by this category of adolescents. Based on the above, the importance of the current study can be determined as follows:

- Lack of scientific and research studies on preemptive aggression among middle school students to the knowledge of the researcher

- Give a theoretical view of the proactive aggression of students in the middle stage giving us the opportunity to make a comparison across the culture with other environments

Research objectives: The present research aims to identify:

- The level of proactive aggression among middle school students

- The statistical significance of the pre-emptive aggression according to the sex variable (male-female))

Limitations of the research: The current research is determined by studying the proactive aggression of second grade students in the middle stage of the morning studies of both sexes (males and females) in the center of Babil province for the academic year (2017-2018). 
The Soc. Sci., 15 (1): 38-44, 2020

\section{Terminology}

First: Aggression Aggression defined by Al-Tarah. It is an activity through which a person seeks to cause physical harm or physical pain to another person who is motivated to avoid this behavior or is a behavior that attempts to achieve a certain goal in harming another person [9, 70].

Ali and Ibrahim (2009): It is an emotional behavioral response that may involve a decline in the level of insight and thinking and some often behave aggressively when suffering physical or moral stress [10, 35].

Second: Proactive aggression defined by:

Age (2010): An aggressive behavior aimed at protecting oneself or property against an anticipated aggression or in anticipation of an anticipated attack that is the initiative to attack others before they attack us [11, 252].

Acet: An internal incentive for the individual rather than a reaction to an external provocation with the intention of obtaining some gains to which he has no right, regardless of whether there is an external provocation or not.

Theoretical definition: In light of the previous definitions, the researcher adopts the definition of Acet which is theoretically defined as the closest to the current research topic.

Procedural definition: The degree to which the students of the research sample obtained their responses to the items of the proactive measure of aggression prepared to achieve the research objectives.

Chapter II/theoretical framework and previous studies The concept of proactive aggression: The term proactive aggression of modern terminology in the literature of education and psychology and the workers in the field of psychological and educational, it includes violent physical violence and verbal violence is large and includes a review of the power and control and the desire to control the capabilities of other comrades and peers and this behavior exists between students in all stages of education [393,12].

The concept of premeditated aggression is due to Dodge and Coie (1987). This concept was created from the model of frustration-aggression which sees aggression as a state of hostility and an angry reaction to the state of perceived frustration of the individual. Frustration and pressure often result in violence and aggression [13, 1146].

As explained by Andorra in the theory of social learning that there are important people in the life of adolescents such as: parents, teachers and comrades can be counted models from which the social behavior in general and aggressive behavior in particular $[60,14]$.
A number of researchers stressed the importance of the proactive aggression function which is referred to as the desire to reach a specific goal and that adolescents who have proactive aggression use it as a means of gaining power and controlling others or intimidating peers. These adolescents are known as aggressors or "bullying" cold blood [525,15].

Freud recounted that the aggression of man on himself or on others is a natural act of the energy of internal aggression which provokes him and insists on the demand for satiety and rest only if he assaults others, beatings, abuse and murder or assaults himself with humiliation, humiliation, abuse and suicide [248,16].

One of the manifestations of pre-emptive aggression which Fischbach categorized is aggression which is aimed at trying to gain individual privileges or things. Usually, the adolescent does this kind of aggression when he feels that there is something that obstructs his goals and aggression. Others and accompanied by angry feelings $[22,17]$.

Coie et al. has shown that bullying acts are preemptive acts of aggression and that bullying is defined as deliberate, deliberate, repetitive acts aimed at the victim itself which is surrendering to aggression. On this basis, acts of bullying are proactive actions of adolescents. Define pre-emptive aggression through the aggression of the Wasiti or Wassili and the aggression of development [18, 219].

McAdams and Schmidt show that the characteristics of pre-emptive aggression are deliberate aggression and are used by the aggressor to achieve a goal or achieve a personal order. Individuals also use premeditated aggression and their behavior is systematic and pragmatic. For example, "a child pays another child to reach the beginning of the class" [19, 630].

Psychologists presented theoretical visions that explain the occurrence of an aggressive response in all its forms as explicit and explicit as a behavior aimed at satisfying different motivations. Pre-emptive aggression is a form of implicit aggression and notes that the intensity of the aggressive response is directly proportional to the amount of frustration associated with the kind of frustrated motivation. Adler that aggression is the main motive in the life of the individual and the community which is the basis of the desire for differentiation and superiority because life grows towards the various manifestations of aggression of control and power which led him to decide that aggression is the basis of the will of force and the will of the step is based on humanitarian motives [20.3] and is [21, 2].

On the basis of the foregoing, it is possible to clarify the premeditated aggression as an aggressive behavior aimed at protecting the self and property against an anticipated aggression or in anticipation of an anticipated 
attack. Let us initiate an abortive aggression such as preemptive military strikes, meaning preemptive aggression. Or attack others before attacking us [245, 22]. Some concepts related to pre-emptive aggression.

Anger: Although, anger is one of the most basic emotions in psychology, this concept is confused with some of the concepts associated with it such as aggression and pre-emptive aggression. Aggressiveness refers to a complex set of attitudes and judgments that lead the individual to aggressive behaviors. And are evaluated in a negative way and they are present in all people to varying degrees, a combination of complex feelings such as jealousy and envy and hatred and a sense of injustice and hatred and called some of the hidden aggression because it includes harming others psychologically or emotionally (Adil, 2010) The forms of anger according to Namka are.

Healthy anger: It is an emotional reaction logical and acceptable to the physical harm and abuse of the individual and trying to protect himself and this type of anger can be considered healthy.

An unhealthy anger is the result of negative thoughts and feelings which are based on unacceptable methods to justify anger and this type requires a high self-awareness to control and control it. If uncontrolled, it is a destructive outrage [23, 59].

Bullying: Refers to bullying as a form of aggression in which there is no balance of forces between the bullying and the victim. The bully is always stronger than the victim and bullying may be verbal, physical or psychological, direct or indirect [24, 123].

Bullying occurs during various school activities when a student or a group of students uses their power to hurt others because bullying is a form of school violence. The bullying force is either a physical strength or a social level or a difference in their chronological age [25, 161].

Violence: Is a highly emotional behavioral response that may involve a decline in the level of insight and reflection and violence in the use of forces derived from equipment and machinery which in this sense refers to the extreme form of aggression. Violence is the attempt to inflict serious bodily harm [26, 100].

Psychologists believe that violence is an instinctive behavior accompanied by hatred and love of destruction whose purpose is to release pent-up hostility toward others. Violence may also be the result of extreme frustration and inability to sublimate, rise or restrain $[27,75]$.

\section{Proactive objectives of aggression}

First; compulsion and coercions: Aggression is often a coercive attempt. Attackers hurt their victims in an attempt to influence their behavior to force them to do what they want.
Second; Power and hegemony: Proactive aggression involves greater coercion. It is often aimed at maintaining and strengthening power and may strike or push adolescents in an attempt to impose their own way of asserting their dominant positions in their relationships with their peers. They try to show that they are not secondary to them and studies in this field I have repeatedly explained that when a family member attacks another, it is usually the stronger that oppresses the weak and makes him the victim. This is consistent with the belief that aggression increases with self-esteem.

Third; harmless and harmless goals: A number of sociologists see most aggressive attacks as more than a desire to inflict harm on one of their victims. The main purpose is that the aggressors act rationally. This perspective confirms that the attackers have another goal of building their own values. For example because of the observation of the student and in the revolution of anger, the teacher hit him that this attack is driven to the extreme by the internal motive and aims to hurt the abuser while in contrast to the sociologists confirm that there are certain goals than the targeted harm shows the teacher that beating the student. He can assert his control over him and teach him not to bother him again $[28,119]$.

The theories that explained the aggression preemptive The theory of frustration-aggression: One of the most famous scholars of this theory (Dollar Dollard, Miller Miller, Sears Sears) who agreed that proactive aggressive behavior appears as a result of frustration [29, 27].

Frustration is an excitation that can call for responses from the individual including aggression, depending on the type of responses the individual has learned in dealing with cruelty and pressure. These responses can be seeking help from others, withdrawing from the situation, trying to solve the problem, overcoming it or resorting to alcohol, drugs, aggression or the use of basic defense mechanisms. These are the most likely responses. If aggression in the past leads to frustration, the potential for future aggression will increase, and the same is true for any Jabhakhry [30.211].

And focused on these social scientists on the social aspects of aggressive behavior has been presented the first image of this theory on the assumption that there is a link between frustration and aggression where there is a link between frustration and aggression as a response, the essence of the theory in the following:

*All frustrations increase the likelihood of aggressive reaction. * All aggression presupposes the existence of a former frustration [31, 315].

Social learning theory: This theory is no less important than other theories that dealt with aggressive behavior which was formulated by the American psychologist 
The Soc. Sci., 15 (1): 38-44, 2020

(Bandura) and emphasizes this theory on the role of social learning has been interested in studying the human in his interaction with others and the personality in his perception is understood only through the social context his behavior is shaped by observing the behavior of others. This theory summarizes that aggressive behavior is a social behavior learned by modeling or simulating role models. Individuals learn from teachers, parents and friends and follow the media's methods and information that enable them to practice it and when it gets promoted as a result of aggression, others tend to imitate it in its behavior leading to the generalization of that behavior to other people [32, 18].

In the view of the authors of this theory that proactive aggression is the behavior of the learner as well as other types of behavior and the idea that the individual learns the aggressive behavior of the environment in which it exists as a result of the observation that the use of violence and aggression contributes to the achievement of goals $[33,40]$.

Previous studies: The previous studies are an important part of the frame of reference and the theoretical background of the research as well as the access to them is an important step in the preparation of the research and on this basis will be presented.

The first axis: Studies that dealt with proactive aggression. Arab studies study. (Proactive aggression and aggressive reaction and their relationship with empathy and cognitive sympathy for the hearing impaired).

This study was conducted in the cities of Najran and Abha in the Kingdom of Saudi Arabia. The aim of the study was to find the relationship between aggression (pre-emptive, reflexive) and empathy (emotional and cognitive) for the hearing impaired and the types of aggression characterized by the hearing impaired. The sample was divided into 83 male children (49 female). The researchers applied the measure of aggression (Dodge and Coie, 1987). The researchers translated and localized the two measurements and codified them to the Saudi environment and used the following statistical means: Arithmetical, standard deviation and t-tes test (SPSS). The results showed that there is a negative correlative relation between the pre-emptive aggression, the reaction aggression and the emotional and cognitive empathy of the hearing impaired. There are statistically significant differences between the degrees of the students with hearing impairment on aggression scale verb) in favor of post-aggression reaction [34, 153].

Foreign study: Study (Suter et al., 2015) implicit and explicit self-esteem as predictors of reactive and proactive aggression in adolescent boys and girls. (Implicit and explicit self-esteem as a sign of reactionary aggression-in adolescents).
The study aimed at examining the differences between the sexes and their relation to implicit and explicit self-esteem and aggression of reaction in the adolescents. The sample consisted of (118) individuals, distributed among 60 males and 58 females. The Rosenberg for implicit self-esteem and a measure of reactive aggression was used. The results showed that females with low implicit self-esteem showed a more aggressive reaction than females with a high implicit implicit estimate. These different types of self-esteem were not associated with response aggression. The male has acted as he has not reached the atmosphere. A high correlation between the types of self-esteem and aggression proactive gender Krihama of research sample laboratories (35.2).

\section{MATERIALS AND METHODS}

Research methodology and procedures: Since, the current research aims to know the proactive aggression of middle school students, the researcher adopted the descriptive approach because it is the appropriate approach to the nature of the research and its objectives which means describing what is being and gives a precise description of the current phenomenon and its composition and processes and prevailing conditions. The descriptive approach includes collecting, measured and interpreted [36, 370].

Community of research: The current research community consists of (22846) middle school students in the center of Babil governorate for the morning study of males and females distributed among (43) middle schools of second grade students, the average number of male students (11452) students and females (11394) with a final sample of (458) students.

Sample of research: In order to obtain a representative sample of the original society in the current research, the researcher took the following steps $(37,104)$.

Writing the names of middle school schools in the center of Babil province on paper, after dividing the research society into male schools and female schools. Then the researcher wrote the names of the schools on small scraps of paper that put the names of the male schools in the bag and the female schools in the bag. The male schools were: Jabir Al-Ansari, Al-Sadouq, Naf'aIbn Hilal, Al-Rafidin and Safi Al-Din. The female schools were Al-Muroj, Jenin, Basrah, Safa and Safiya Bint Abd Al-Muttalib.

Selection of (458) male and female students in the intermediate stage in the random stratified manner. They represent $(2 \%)$ of the original society of the current research, divided by gender (male, female). 
Instruments of research: Since, the current research aims to identify the proactive aggression among students in the middle stage, so, the presence of a tool that has the characteristics of the psychometric to achieve the objectives of the research as follows:

The scale of proactive aggression: Because of the lack of a modern measure in the Iraqi educational environment, it required the construction of a measure by identifying the theoretical premises and the basic needs on which we base its construction and in order to find more realistic paragraphs derived from positions related to the sample of the research. The researcher presented an open questionnaire to (40) male and female students with (20) questionnaires for males and (20) questionnaires for females, after looking at literary literature Ge and through the questionnaire.

Open the researcher formulated (30) paragraphs for the current scale and the alternatives for this measure were determined on the Lycert triangular scale (always, sometimes, never).

The true honesty of the search tool is based on the fact that a number of specialized arbitrators determine the veracity of the paragraphs to measure the phenomenon or attribute that has been developed for it by adopting the percentage or using the square (Ka 2) and the judgment issued by them is an indication of the validity of the tool $[38,138]$. Therefore, the researcher presented the scale to a group of arbitrators to ascertain the validity of the paragraphs and the paragraphs were valid for all what was put for it and was retained all paragraphs and the number of (30) on the research sample.

The validity of the scale was calculated using the validity of the construction by two methods. The first is the finding of the discriminant force of the paragraphs in the two groups. Using the t-test of two independent groups, the significance of the differences between the mean scores of the lower and upper groups was tested by comparing the calculated $\mathrm{T}$-proactive aggression in tabular value. It was found that the differences are statistically significant at the level of significance (0.05). The calculated value is higher than the tabular value (1.97) and the degree of freedom (214) for all the paragraphs of the scale and thus has a good ability to distinguish. The correlation coefficients ranged between (531.0 and 201.0). It was found that all the scales were characterized by a good correlation coefficient.

Stability of the scale: Extract the stability of the scale in two ways: the method of retesting the value of the stability coefficient of the scale $(83,0)$ which is a good stability value can be relied upon and the other way is the method of the equation Vkronbachbach the value of the stability coefficient extracted in this way $(85,0)$ a good coefficient of stability.
Statistical means: The researcher used the statistical file (SPSS) to process the data as follows.

Box kay: To find out the difference of opinions of the arbitrators on the validity of paragraphs of the standards of aggression proactive. Pearson correlation coefficient to find the correlation between:

- $\quad$ The degree of the paragraph by the total number of measurement paragraphs (discriminatory force)

- $\quad$ The degree of each paragraph and the area to which it belongs to the scale

- The value of the stability coefficient by the re-test of the two measures of pre

FCronbach: To find the value of the stability coefficient of the measure of pre-emptive aggression.

Two way tentative test: To find the discriminant force of the scale sections in the two-way method of the two scales.

Discriminant force: The test of two independent independent samples: to find the discriminant force of the scale sections in the two sets of the two sets of scales.

Statistical: The test of two independent independent samples: to determine the statistical differences of the search variables according to the gender variable (male, female).

Among middle: A single sample test to identify the level of pre-emptive aggression among middle school students.

\section{RESULTS AND DISCUSSION}

Chapter four; Presentation, discussion and interpretation of the results:

Objective 1: To identify the level of aggressive aggression among middle school students. In order to achieve this objective, the measure of pre-emptive aggression was applied to the 458 students. After the data was emptied and statistically processed, the arithmetical mean and the standard deviation of the student's scores were found. The mean of the sample scores was 675,38 and a standard deviation of $(948,6)$ and comparing this average with the mean average of 60 . To determine the difference between the real mean and the mean average of the sample, the t-test was used for one sample 65 which is larger than the grand scale (1.96 ). At the level of significance (05.0) and degree of freedom (457) and in favor of the satisfactory medium and this result shows that the members of the research sample to be proactive aggression is weak. 
The second objective is to identify the statistical significance of the aggressive aggression according to the gender variables.

In order to determine the difference in the level of aggressive aggression in the research sample according to sex variables (males and females), the researcher used the tit test for two independent independent samples. The calculated t-value (808.4) which is greater than the tabular value $(96.1)(456)$ and for males $(539,40)$ which is larger than the mean of adult females (446.37). Thus, statistical differences indicate that males are more aggressive than females.

\section{CONCLUSION}

In the light of the findings of the researcher in the current research, we can conclude the following: the students of the middle stage have a low level of proactive aggression and this shows the impact of compliance with the laws set by education and the role of the educational guide in educational guidance and problem solving.

There are statistical differences in the proactive aggression between males and females and that males are more aggressive than females.

\section{RECOMMENDATIONS}

The results of the research findings of the researcher recommends the following the need for attention and care for middle school students by parents and teachers and to document their emotional relationship as they are going through a critical stage in their lives. Increase the attention to the role of the educational guide and accept its guiding functions and active participation in school activities and the councils of parents and teachers all.

Proposals: In light of the current research results, the researcher proposes several studies including. Training program to reduce the aggression of pre-emptive students in the other stages of study. Knowing the factors that increase the appearance of proactive aggression. The effect of proactive aggression in other variables (educational achievement and motivation to learn).

\section{REFERENCES}

Adli, N.A., 2010. Emotions Growth and Management. University of Mustansiriya, Baghdad, Iraq,.

Age, M.K., 2010. Sociology of Violence. 1st Edn., Dar Al Shorouk for Publication and Distribution, Amman, Jordan,.

Ali, A.H. and Q. Ibrahim, 2009. Violence Against Children. Taiba Foundation for Publishing and Distribution, Cairo, Egypt,.

Dodge, K.A. and J.D. Coie, 1987. Socialzinformation-processing factors in reactive and proactive aggression in children's peer groups. J. Personality Soc. Psychology, 53: 1146-1158.

Dodge, K.A., J.E. Lochman, J.D. Harnish, J.E. Bates and G.S. Pettit, 1997. Reactive and proactive aggression in school children and psychiatrically impaired chronically assaultive youth. J. Abnormal Psychol., 106: 37-51.

Quiroz, H.C., J.L. Arnette and R.D. Stephens, 2006. Bullying in schools: Fighting the bully battle. National School Safety Center, Thousand Oaks, California, USA. http://webcache .google user content.com/search?q=cache:8BWSOrDZe7IJ:teac hingconditions.org/archives/566 + \&cd=3\&hl=en\&c $\mathrm{t}=\mathrm{clnk} \& \mathrm{gl}=\mathrm{pk}$.

Suter, M., S. Urben, S. Pihet, C. Bertoni and J. de Ridder et al., 2015. Implicit and explicit self-esteem as predictors of reactive and proactive aggression in adolescent boys and girls. J. Adolesc. Family Health, 7: $1-29$. 